\title{
National Education Policy 2020 and Its Comparative Analysis with RTE
}

\author{
Dr. Saroj Malik, Asst. Professor
}

SCERT/DIET NCT OF DELHI, India, Dr. Meena Kumari, Associate Professor, Chaudhary Devi Lal University, Sirsa (Haryana) India

Email - sarojmalik8@gmail.com

\begin{abstract}
A child's future depends on the form of education he/she receives. "Education begins at home", there is no truer sentence, but the education a child acquires at school is just as important to mold the lifestyle of the child. Their career, psyche, mentality, connection with society depends on the education received at school. And a well-defined and well-planned education policy helps for the growth of a nation's economy and social position. Based on the culture, tradition, and societal view, a country adopts an education policy. And with the growth observed in our country's most valued possession, the intellectual youth, the adoption of a new education policy seems to be a progressive thought. This paper concentrates on highlighting the innovations and new adaptions in NEP 2020 along with its comparison with the existing policy, merits, implications, and improvements.
\end{abstract}

KEYWORDS: National Policy on Education (1968), New Education Policy, NEP 2020, Overview, Analysis, Merits, Predicted implications, Improvements National Education Policy 2020 and Its Comparative Analysis with RTE

\section{INTRODUCTION:}

While quantitatively India is inching closer to universal education, the type of education the students in India receive has been questioned. With the boost in population, constructing schools nearer to students living habitats became common; this was done intending to increase enrollment. Thus, creating an escalation in the number of schools. With nearly 900 universities, 40,000 colleges, and 15 lakh schools, India lacked in providing qualitative education to students [4,5]. Also, many of these institutions are small-sized and are running single-program and not the multidisciplinary style of higher education which is a must in the country for the 21 st century [3]. In 2019 , about $27 \%$ of the Indian population was observed to be youngsters of the age 0-14year category, 67\%were of the 15-64 age group, hence by 2030 it is expected that India will have more than $69 \%$ of youth.

Improving the form of education given to the youth workforce of current and future times is a burden in itself. This burden was placed on the committee formed headed by K Kasturirangan, Chairman of the Draft Committee of National Education Policy, and the others the new policy was drafted and presented at the Assembly in 2019[3]. After approval, on $29^{\text {th }}$ July 2020, the new National Education Policy was launched [8].

The reforms, detailed in the Policy, provide an upgrade to the Indian Education model. It replaces the current $10+2$ education model with the 5+3+3+4 model and mandates education from 3 years of age, unlike its predecessor which mandates education from 6 years of age [3]. It is expected that a transformation will be seen in the Education System by 2021.

\section{OBJECTIVES:}

Keeping in mind the positiveness and merits of NEP 2020, this study aims at:

1. To highlight,studyand identify the innovative ideas the policies of NEP 2020

2. To comparethe National Policy of Education 1986 and its reforms with National Education Policy 2020

3. To highlight the merits of NEP 2020.

4. Predicting required improvements to NEP 2020

\section{HISTORY OF EDUCATION IN INDIA:}

With universities like Taxila and Nalanda, India has always given prompt importance to education. India's educational history is painted in awe with great Sages and Monks as Gurus. But there seemed to be one fault with the earliest system. With the point "King son becomes a King" and the classification of society into four classes was the main issue in this education system. Brahmin class guarded the Vedic Knowledge, the Kshatriyas were the ruling class, the Vaishyas were the trading class and Shudras were the working class. Children of these classes were educated according to their bloodlines and no education was ever imparted to the Shudra class. This system may have been good for ancient times, but with the development of education and society in the other parts of the world, India lacked the skilled workforce and intellects required to develop the country. Illiteracy was becoming a great issue.

Acknowledging the future of the country, the post-independent 
government implemented a scheme in 1968. Under Prime Minister Indira Gandhi, National Policy on Education was adopted. The new policy aimed at removing divergence in the education system and provided equal opportunities to all children under the age of 14 to study. [7] This policy gave importance to spreading awareness of education. This policy was a big change in the history of the Indian education system. It followed a 10+2 system. In 1986, this policy was reformed; thisreformed policy was to increasing applications of scholarships, adult education, increment in the recruitmentof teachers from the Scheduled Caste, attractive incentives to enable the poor families to admit their children to school, development of new institutions, and many more. In 2002, under the $86^{\text {th }}$ amendment to Constitution, the Right to Free and compulsory education was added. This improved the literacy rate in the country but yet the workforce was not efficient. The fragmentation in the higher education system affects the efficiency rate. The causes for this fragmentation are:

- Students step into different disciplines very early on

- Lack of presence of Higher Education in rural areas

- Absenceof autonomy for teacher and institutions changes in Higher Education to attract students

- Insufficient and inappropriate resources for career management

- Absence of growth in faculty and institutional leaders

- Fewer opportunities to conduct research and innovations at most of the universities and colleges

- Weak governing bodies and leaders at higher education institutions

- The corrupted regulatory system that allows the growth of look like colleges that hinders excellent and innovative institutions

In 2030, India will be one of the youngest countries with the third-largest economy, and this economy will be boosted not by the natural resources of the country butby the growing intellectual resources. To help the growing intellectuals, the government seems to have come up with the right scheme, the National Education Policy 2020.

\section{STUDY OF NEP 2020:}

The National Education Policy of 2020 focuses on India centered Education. The policy was drafted concerning the heritage, history, culture, tradition, and values of the country. This Policy aims at providing a multidisciplinary and interdisciplinary liberal education.[1]

\subsection{Curriculum and Pedagogy of Schooling in NEP 2020:}

Unlike the previous policy with the $10+2$ system, NEP 2020 introduces the $5+3+3+4$ curriculum. Pre-school to Grade 2 being the Foundational Stage, Grade 3 to Grade 5 being Preparatory Stage, Grade 6 to Grade 8 being the Middle Stage, and Secondary Stage being Grade 9 to Grade 12. The curriculum in each stage will be as mentioned below: [3]

\subsubsection{Foundation Stage: Pre-school to Grade 2}

The Foundational Stage of schooling is based on Early Child Care and Education based learning. In these foundational years, NEP 2020 introduces a flexible, multilevel, play - participate discover based system which aims to teach the young ones in the local language/mother-tongue and other languages. Most importance is given to making them understand basics like colors, shapes, sounds, movement, then move on to subjects like games, elements of drawing, painting, music, and the local arts, and also teach them various socio-emotional skills relating to their curiosity, patience, cooperation and improve their teamwork, interaction, and empathy, which act as preparedness for school.

\subsubsection{Preparatory Stage: Grade 3 - Grade 5}

Based on statistics, many students fail in higher classes due to a lack of Foundational Literacy and Numeracy (FLN). Without basic literary knowledge and numeracy knowledge, students who fall behind or score low have been seen to maintain the same status quo in higher education. To instill these foundation skills in the students, the next three years of the curriculum are focused on improving reading, writing, speaking, and their knowledge of Physical Education, art, languages, science, and mathematics.

\subsubsection{Middle Stage: Grade 6 - Grade 8}

The middle stage, with three years of education, focuses on building a more formal setting of education. In this stage, the students will be introduced to subject teachers, who will impart more abstract knowledge of subjects like Science, Mathematics, Social Sciences, Arts, and Humanities. The teaching style is based on learning, discussions, and exploring interdisciplinary relations.

\subsubsection{Secondary Stage: Grade 9 - Grade 12}

The four years of the secondary stage is subject-oriented learning. This stage focuses on allowing the student to choose 5 - 6 subjects from the multidisciplinary study. In this stage, the students are encouraged to concentrate more on subjects with greater depth, critical thinking, and focus on life goals. There will greater flexibility in choosing subjects including ones like arts, vocational training, and physical education. This allows students to expand their horizons and helps them to be more prepared for higher education. 


\subsection{The architecture of Higher Education Institutes (HIEs):}

By this policy, the focus of HIEs is on improving the professional skills of the workforce. Higher education has been divided into the same three categories with a change in curriculum, like,[1]

- Under-graduation Education: The Undergraduate degrees will be of either 3- or 4-year duration. During these years' students have a choice of multiple entries and exits like a certificate upon clearing the first year, after passing the second yeara diploma, or after passing the third yeara Bachelor's degree. The four years undergraduate degree program comes with majors, minors, and research projects.

- Post-graduation Education: The Master's degree will be one year or two years course based on their previous Bachelor's degree duration taken up by the student or they can choose an integrated five-year degree,the main aim of which is high-quality research in the final year. The Masters' degree will prioritize the research component to improvise professionalism in students and to prepare them for a research degree.

- Research: The research stage of a minimum of 3 or 4 years, consists of pursuing high-quality research leading to a Ph.D. in any core subject, multidisciplinary subject, or interdisciplinary subject and it may be full-time and part-time study. During Ph.D. they will undergo 8-credit coursework in subjects of teaching/ education/ pedagogy which will be related to their chosen Ph.D. subject. The one-year MPhil program will hence-forth be discontinued.

Based on the above format of the curriculum the HIEs will be divided as below [3]:

1. Research Universities: With the priority of research, these universities will have a curriculum based on cuttingedge research and encouraging new researches. The universities will have programs from Undergraduate to $\mathrm{Ph}$.D. The aim is to have world-class research universities and compete globally.

2. Teaching Universities: The aimhere is to provide highqualityeducationacrossallHIEcourses likeUndergraduate, Masters,Doctoral; may these beProfessional, Vocational, Certificate, orDiploma programs.

3. Colleges: These institutes will focus on providing education to masses with courses across disciplines and fields like undergraduate programs, with the diploma and certificate programs included, including vocational and professional.

\subsection{Teaching faculty:}

To match the curriculum and have an improved teaching standard, the below steps have been taken:[3]

- B.Ed. programs will be of four years with a multidisciplinary settee.

- For those from different master's degrees or four-year bachelor's degrees, the B.Ed. course will be for one year.

- B.Ed. and D.El.Ed will be considered under the banner of B.Ed.

- Teacher education in universities will be stage-specific; based on the educational stage they wish to teach.

- $\quad$ Specialized teachers, for arts and vocational courses or local art, literature, crafts are trained with a special course of one year.

- All B.Ed. programs will include educatingon subjects like FLN, multidisciplinary teaching and evaluation, tutoringSpecially-abled Children, technology in education, and more.

- Standalone teacher education institutions will be closed or merged or converted to HEIs.

- Volunteers, ex-government workers (includes exmilitary), and counselors are encouraged to educate children by joining local schools.

With the idea, quote: "If literate members of society help to teach a student or a person, it would change the country's literary landscape."

\subsection{Adult Education:}

Being an illiterate adult in a growing society is just difficult. To improve the living of those adults and to educate them the government has taken up the below steps:[3]

- The curriculum is based on improving FLN, life skills subjects like finance, digital, health care, child care, family welfare and others like vocational skills, basic education, and higher education (if they wish to)

- The curriculum is planned under a new section added to NCERT

- Adoption of CIAE - Central Institute of Adult Education

- Training a highly-skilled cadre for Adult Education Centers

- Introducing lifelong education as a part of Adult Education for neo-literates and targeted beneficiaries.

\subsection{Rashtriya Shiksha Aayog (RSA):}

It's known that this Policy emphasizes the creation of highly 
intellectual society and recognizes the multidimensions of education and its holy nature. To reach its goal the policy recognizes the need to change the current governance of education. Under this policy, the following steps are to be taken:

1. A new Apex body named RSA or NEC (National Education Commission) will come into force.

2. Ministry of Human Resources Development will be reassigned tothe Ministry of Education.

3. The Prime Minister will head the RSA as the chairperson.
4. New regulatory bodies are set up, namely the National Higher Education Regulatory Authority, General Education Council, Higher Education Grants Council, National Research Foundation

5. The RSA will be responsible for the application, modification, development of the vision of education. Thus, RSA is the supreme decision-maker. The other regulatory bodies like NAAC, NCERT, etc. fall under RSA.

\section{COMPARISON OF NEP 2020 AND NPE 1986:}

Though NPE 1968 aimed at modernizing education in India, it failed to bring out the desired result. The below table gives out the comparison between NEP 2020 and NPE 1986.

No $\quad$ NEP $2020 \quad$ NPE 1968

$1-$ It concentrates on the interdisciplinary and multidisciplinary form of education.

Focus is on bettering education and workforce in the country

3 It has $5+3+3+4+4+1$ form of curriculum

4 The preliminary education begins at age 3 .

The Pre-universities allows a choice of subjects in fixed streams (Science, Arts, or Commerce)

Entrance into undergraduate courses at HEIs is

6 based on NTA's (National Testing Agency) scores excluding private HEIs

Post-graduation focuses on specialization and research.

There is no hard separation among subjects,

8 vocational, academics, curricular, extracurricular, non-curricular, sciences, arts, or otherwise.

Focuses on early childhood care along with education hence arts, music, and aesthetics are included in the foundational stage.

Students are free to choose interdisciplinary subjects from any stream

Exams are an integrated part of learning. The

11 teaching faculty at the respective institute is responsible for conducting exams.

To join as a tutor at HIEs Ph.D. with the clearance of NET/SLET is compulsory

About 100 foreign Universities are permitted to operate in the country

Teaching methods are knowledge, fieldwork, and research-oriented

Multiple entries and multiple exits are allowed
It concentrates on the overall development of students

Focus is on improving education in the country

It has $10+2+3+2$ form of curriculum

The preliminary education begins at age 6 .

The Higher education of four years allows the multidisciplinary choice of subjects.

Entrance into undergraduate and higher courses is dependent on entrance exams at the state level, national level, or by the private institutes

Post-graduation focuses on specialization only.

The hard separation among subjects is seen.

Focuses on early childhood care.

Students are free to choose any subjects around the fixed stream (Science, Arts or Commerce)

Exams are independent of learning. The exams conducted are evaluated by affiliating universities

To join as a tutor at HIEs, Masters with the clearance of NET/SLET is compulsory

No foreign universities are permitted to operate in-country.

Teaching methods are knowledge and fieldwork oriented

Lateral entry in few fields is allowed whereas multiple entries or exits aren't allowed. 
16

Online libraries with membership including online books and online journal are to be

Only multidisciplinary institutes are encouraged.

Single disciplinary institutes are expected to turn to multidisciplinary institutes or must be shut down and modified into monuments or libraries.

Students are expected to engage in social programs as it is compulsory and is equal to a whole semester

To teach at any stage in schools' teachers are expected to complete integrated B.Ed. course which is for four years and this is compulsory
Physical libraries were improved with betterment in faculty, books, and journals

Single and multidisciplinary both institutes are encouraged

Students' involvement in social programs is optional.

To teach at the secondary education stage teachers are expected to complete their bachelor's degree and B.Ed. which is five years of learning

Only selected and approved institutes are allowed to conduct online and distance learning

\section{MERITS OF NEP 2020:}

With the intensive stress on multidisciplinary education and industrial education, this policy is expected to revamp the Indian education system by 2030 . With the policy being implemented from June 2020, the changes in the education system are expected to be seen in the next two to three years. The merits of NEP 2020 are listed below:

- With the changes in the pedagogy and curriculum of education, the $5+3+3+4$ system is expected to bring a new wave of intellectuals in the next 10 years. And this group of youth is said to be the most important resource in India.

- The reforms to the adult education system attract adults to join and begin or complete their incomplete education.

- The multidisciplinary approach to syllabi ensures the students excel in the subjects they have chosen.

- As the policy is student-centric and has a competencybased credit system, a student can evaluate himself/ herself by taking courses through SWAYAM, MOOCs (Massive Online Open Courses), or ODLs (Online Distance Learning) at their own pace.[1]

- With the introduction of vocational classes into the school curriculum, the heritage of the country prospers. It also promotes the growth of a skilled workforce.

- The volunteer system, wherein volunteers are accepted at local schools to educate students, helps to best the quality of education.

- With the establishment of RSA, the corrupted regulatory system will be brought under control.

- Inclusion of research study into the curriculum promotes the students to explore the depth of their chosen subjects

- Approval of the establishment of foreign universities in the country gives more chances for global exposure
- Arts and music are introduced at the early stages of education allowing the growth of the culture of the country

- $\quad$ The differentiation in the types of HIEs helps the idea of a limited and burdenless but effective curriculum. This also helps the students to study better based on their choice of institution

- Integrated courses lessen the burden of studying but yet gives a better outcome.

- Retaining schemes like Midday Meals still attracts the students.

- With the installation of preschools and primary schools near Anganwadis and closer to habitats, the percentage of enrollment of students is expected to grow as it reduces the burden of commute.

- The change in the education system, $5+3+3+4$ system, will increase the number of schools and HIEs and hence will reduce the privatization of education

- The compulsory accreditation of HIEs, every five years, keeps in check the quality of education provided at HIEs.

- The introduction of Online and distance learning in every HIEs helps to promote education even in remote rural areas.

- The improvement to the National Scholarship Portal encourages the students to excel at studies and scholarships also improve enrollment percentages.

- Professional education is bound to improve the quality of the workforce by 2045 .

\section{IMPROVEMENTS TO BE INTRODUCED TO NEP 2020:}

Every good thing seems to have flaws. Though NEP 2020 seems to be perfectly drafted without flaws, it needs improvement. The improvements are hence suggested below:

- $\quad$ Retired professors are to be allowed to educate and guide research students irrespective of their age. 
- $\quad$ Publication or patent must be made compulsory during post-graduation courses to encourage research.

- Earn while learn must be introduced with vocational training.

- Students in the secondary stage, HIEs must be encouraged to take up SWYAM, MOOCs, or ODLs to allow them to explore their capabilities.

- The process of patent filing and evaluation must be improved. Instead of the current $3-6$ years, the duration should be reduced.

- Based on teaching capabilities, teachers must be evaluated regularly and non-performers must be removed.

- Though completely unavoidable, lobbying and favoritism must be kept in check at the stage of appointment and accreditation.

- Scholarship students must be awarded tech facilities to help them improve.

- Online-contents like books, journals, papers, patents, etc.,must be made freely available to every student registered to HIEs.

- Multiple entries and exits in the undergraduate system may be misused hence for re-entry the students must be made to attend exams based on the curriculum of their previous class.

- Students or interested students who failed to complete schooling, irrespective of the grade they dropped out at, due to various reasons must be allowed to attend an exam equivalent to the exam of grade 12 . Based on the result of this exam and NTA scores they must be allowed to admit to HIEs.

- Basic health care classes must be introduced in the Secondary stage of schooling.

\section{CONCLUSION:}

This policy, as expected has a lot of pluses but still needs to be improved. With regular updates in its policies, NEP 2020 may turn out to be the best policy in the field of education and human resource. As the saying goes, "A mad king misuses his power and drags his country to sewers", the policy if mishandled may prove fatal. In a country riddled with issues like favoritism, corruption, lobbying, etc., the misuse of policy is natural.

Also, the hopes that this policy brings to people in need is great. NEP 2020 with student-centered ideology, an improvement is expected in the education system and workforce by 2030 .
Not only the younger generation, with the focus on adult education the literacy rate is expected to improve in India. With a multidisciplinary approach to curriculum, students get to study subjects of their choice. Due to attractive scholarship offers, study methodology, credit-based system, and curriculum, the percentage of enrollment is expected to increase. The heritage and culture are also uplifted with the addition of vocational classes and art and music classes, and with the inclusion of aesthetics as a part of the curriculum we can expect the youth to have a better lifestyle. With this, we can conclude, hopes of having a fully developed country is not far.

\section{REFERENCES:}

1. Aithal, P. S., \& Aithal, S. (2019). Analysis of Higher Education in Indian National Education Policy Proposal 2019 and its Implementation Challenges. International Journal of Applied Engineering and Management Letters (IJAEML), 3(2)

2. Aithal, P. S., \& Aithal, S. (2020). Implementation Strategies of Higher Education Part of National Education Policy 2020 of India towards Achieving its Objectives. International Journal of Management, Technology, and Social Sciences (IJMTS), 5(2),

3. Aithal, P. S., \& Aithal, Shubhrajyotsna (2020). Analysis of the Indian National Education Policy 2020 towards Achieving its Objectives. International Journal of Management, Technology, and Social Sciences (IJMTS), 5(2), 19-41. DOI: http://doi.org/10.5281/zenodo.3988767

4. Document on National Policy on Education 1986: https:// www.education.gov.in/sites/upload_files/mhrd/files/ upload_document/npe.pdf

5. Draft National Education Policy 2019: https://www. education.gov.in/sites/upload_files/mhrd/files/Draft NEP_2019_EN_Revised.pdf

6. Education in India: https://en.wikipedia.org/wiki/ Education_in_India

7. India beats China in Schools but Lags in Education: https://timesofindia.indiatimes.com/ india/india-has-3-times-more-schools-than-chinabut-they-are-a-mess/articleshow/68616961.cms 
8. Kapur, Radhika. (2018). Problems in the Indian Education System. https://www.researchgate.net/ publication/323700593_Problems_in_the_Indian_ Education_System

9. Kaur, S. (2020). Progress of IBSA Countries Towards Universal Primary Education: A Comparative Analysis. MIER Journal of Educational Studies Trends \& Practices,

10. National Education Policy 2020: https://en.wikipedia.org/ wiki/National_Education_Policy_2020
11. National Policy on Education: https://en.wikipedia.org/ wiki/National_Policy_on_Education\#: : text $=$ the $\% 20$ national $\% 20$ website.-, 1986,Scheduled $\% 20$ Caste $\% 20$ (SC)\%20communities

12. Plecher, H. (Oct 20, 2020). Age distribution in India 2009-2019 https://www.statista.com/statistics/271315/ age-distribution-in-india/

Citation: Dr.Saroj Malik "National Education Policy 2020 and Its Comparative Analysis with RTE". American Research Journal of Humanities and Social Sciences, Vol 7, no. 1, 2021, pp. 1-7.

Copyright ( 2021 Saroj Mallik, This is an open access article distributed under the Creative Commons Attribution License, which permits unrestricted use, distribution, and reproduction in any medium, provided the original work is properly cited. 